\title{
CONSTITUIÇÃO ECONÔMICA E DESENVOLVIMENTO: A ATUAÇÃO DO MUNICÍPIO NA ECONOMIA LOCAL POR MEIO DAS MOEDAS SOCIAIS
}

ECONOMIC CONSTITUTION AND DEVELOPMENT: THE MUNICIPALITY'S

PERFORMANCE IN THE LOCAL ECONOMY THROUGH SOCIAL CURRENCIES

Fernando Afonso M. de Melo * | Willame Parente Mazza** | Rafael de Sousa Araújo***

\section{RESUMO}

O presente artigo tem como objetivo estabelecer uma interpretação da constituição econômica voltada para uma maior participação dos municípios no processo de desenvolvimento local. Dentre as possibilidades de atuação se evidenciam as moedas sociais. Desenvolve-se uma interpretação do conceito de constituição econômica e como a mesma se relaciona com a temática do desenvolvimento. Ao problematizar o modelo de federalismo brasileiro e a dependência entre os entes federados, buscou-se compreender o papel do município dentro do Estado brasileiro e as possibilidades de consecução de um projeto de desenvolvimento local. Ainda, ao se reconhecer que a constituição econômica pode ser direcionada para a ampliação das alternativas do poder público municipal no processo de desenvolvimento, assentou-se uma análise de como as moedas sociais podem ser um dos instrumentos dessa atuação. Conclui-se que diante de um quadro de dependência dos municípios em relação à União, a constituição econômica pode servir como instrumento de ampliação das competências municipais em matéria econômica relacionadas ao processo de desenvolvimento local. Nessa linha, as moedas sociais podem ser instrumentalizadas como elemento criativo, passível de implementação pelas gestões municipais. O trabalho consiste em uma revisão de literatura, tendo por base a doutrina e as diretrizes constitucionais relacionadas ao direito econômico e às competências dos entes federados. Palavras-chave: Constituição desenvolvimento; município.

* Mestrando em Direito pela Univers Universidade Estadual do Piauí (UESPI).
fernandoammelo96@gmail.com

** Pós-Doutor em Direito pela Universidad de Sevilla (Espanha). Doutor em Direito Público pela Universidade do Vale do Rio dos Sinos (UNISINOS). Professor Adjunto da UESPI. Auditor Fiscal. willamemazza@uol.com.br

*** Doutorando em Economia pela Universidade Federal da Paraíba (UFPB). Mestre em Economia pela Universidade Federal do Rio Grande do Norte (UFRN). rafaelaraujo05@hotmail.com
This article aims to establish an interpretation of the economic constitution aimed at greater participation of municipalities in the local development process. Among the possibilities of action, social currencies are evident. An interpretation of the concept of economic constitution is developed and how it relates to the theme of development. When problematizing the model of Brazilian federalism and the dependence among the federated entities, we sought to understand the role of the municipality within the Brazilian State and the possibilities of achieving a local development project. Still, when recognizing that the economic constitution can be directed towards the expansion of the alternatives of the municipal public power in the development process, an analysis was based on how social currencies can be one of the instruments of this action. It is concluded that in the face of a situation of dependence of the municipalities in relation to the Union, the economic constitution can serve as an instrument for the expansion of municipal competences in economic matters related to the local development process. Along these lines, social currencies can be used as a creative element that can be implemented by municipal administrations. The work consists of a literature review, based on the doctrine and constitutional guidelines related to economic law and the competences of federated entities.

Keywords: Economic Constitution; development; municipality. 


\section{SUMÁRIO}

\section{INTRODUÇÃO; 1 CONSTITUIÇÃO ECONÔMICA E DESENVOLVIMENTO; 2 O PAPEL DO MUNICÍPIO NO DESENVOLVIMENTO LOCAL A PARTIR DA CONSTITUIÇÃO ECONÔMICA DE 1988; 3 INTERVENÇÃO DO MUNICÍPIO NO DOMÍNIO ECONÔMICO E AS MOEDAS SOCIAIS; CONSIDERAÇÕES FINAIS; REFERÊNCIAS}

\section{- INTRODUÇÃO}

A Constituição Federal de 1988 inicia com a forma de Estado adotada pelo constituinte, dispondo que a República Federativa do Brasil é formada pela união indissolúvel dos Estados e Municípios e do Distrito Federal ${ }^{1}$.

Segundo Luciano Ferraz "o Brasil desde a Constituição de 1891 adotou a forma federativa de Estado, substituindo o modelo unitário dos tempos imperiais" ${ }^{2}$. Este, tem suas primeiras origens nos Estados Unidos. Assim, "surgiu como resposta à necessidade de um governo eficiente em vasto território"3.

Impende reconhecer que o modelo de federalismo é pautado na convivência harmônica e na comunhão de interesses. Alicerçados em princípios e valores expressos no texto constitucional, todos os entes têm o papel de trilhar seu caminho rumo ao bem-estar comum.

Desse modo, a experiência de federalismo brasileiro demonstrou a adoção de uma forma cooperativa ${ }^{4}$, é o que sustenta Gilberto Bercovici. Logo, há uma repartição de atribuições e responsabilidades para cada ente. "O objetivo primordial da referida repartição é o desenvolvimento equilibrado do Estado brasileiro" 5 , sendo que em matéria econômica não poderia ser diferente.

Entretanto, a realidade destoa do modelo de cooperação anteriormente citado. Ocorre uma concentração exacerbada de competências em favor da União. Fazendo desta, a promotora da política econômica e social; que relega aos centros locais de poder, quais sejam, os municípios, competência extremamente residual que distancia sobremaneira a implementação de um plano de desenvolvimento próprio. A consequência direta é a dependência dos municípios em face da União.

Destaca-se que mesmo "com o crescimento das economias locais e consequente aumento das arrecadações municipais, a dependência de transferências intergovernamentais

\footnotetext{
${ }^{1}$ Artigo 1ㅇ da Constituição da República Federativa do Brasil de 1988.

${ }^{2}$ FERRAZ, Luciano. Município e Federalismo. In: NASCIMENTO, C.V. et al (org.) Tratado de Direito Municipal. Belo Horizonte: Fórum, 2018. p. 29.

${ }^{3}$ MENDES, Gilmar Ferreira. BRANCO, Paulo Gustavo Gonet. Curso de Direito Constitucional. 7. ed. São Paulo: Saraiva, 2012. p. 855.

${ }^{4}$ BERCOVICI, Gilberto. Dilemas do Estado Federal Brasileiro. Porto Alegre: Livraria do Advogado, 2004.

${ }^{5}$ CLARK, Giovani. O município em face do direito econômico. Belo Horizonte: DelRey, 2001.
} 
continua sendo o traço marcante da situação financeira dos municípios brasileiros" ${ }^{6}: 94 \%$ têm nas transferências recebidas pelo menos $70 \%$ de suas receitas correntes ${ }^{7}$.

Desse modo, surge a necessidade de que gestores locais sejam responsáveis pelo desenvolvimento de políticas voltadas ao incremento da atividade produtiva e a uma melhora nos níveis de desenvolvimento local.

$\mathrm{Na}$ tentativa de desenvolver uma reflexão acerca da maior participação dos municípios no processo de desenvolvimento econômico, observa-se que uma interpretação lógica da constituição econômica permite uma ampliação das competências municipais. Assim, o município poderá intervir dentro das especificidades da economia local, ao passo em que poderá ocorrer significativa melhora nos índices de desenvolvimento econômico.

Nos últimos anos, alguns municípios instituíram moedas locais como resposta a um quadro de pouca dinâmica econômica. Buscando superar verdadeiro isolamento do ponto de vista do fluxo de negócios, gestores públicos encontraram na criação de moedas sociais uma ferramenta de incentivo ao comércio local, sendo, portanto, uma possibilidade de atendimento das diretrizes constitucionais voltadas ao desenvolvimento e aos ditames estabelecidos na constituição econômica de 1988.

Logo, o presente artigo visa desenvolver uma interpretação da constituição econômica com a ampliação das possibilidades de intervenção do município no domínio econômico. Propõe-se uma análise da constituição econômica em consonância com a necessidade de que os entes federados busquem o desenvolvimento.

Ainda, o estudo problematiza a dependência dos entes municipais, apontando que o modelo de federalismo brasileiro é um dos elementos intrínsecos à dependência em relação ao ente central. Indica ao final que a ampliação das competências municipais, permite reconhecer maior participação das municipalidades no processo de desenvolvimento local, tendo nas moedas sociais um dos instrumentos de sua atuação.

Por fim, o presente estudo possui caráter bibliográfico e documental, com ênfase na doutrina especializada em direito econômico e nas disposições constitucionais relacionadas à distribuição das competências entre os entes federados.

\section{CONSTITUIÇÃO ECONÔMICA E DESENVOLVIMENTO}

O conceito de constituição econômica não é tema pacífico dentro da literatura jurídica, de modo que, as alterações sociais e econômicas influenciam diretamente a análise da mesma.

Nessa perspectiva, a Constituição econômica seria a decisão sobre o modelo econômico de uma sociedade, que reconheceria uma determinada ordem já existente

\footnotetext{
${ }^{6}$ ANDRADE, Mário Cesar da Silva. Dependência financeira dos municípios brasileiros: entre o federalismo e a crise econômica. Revista Espaço Acadêmico - n. 185 - outubro/2016.

7 FIRJAN - Federação das Indústrias do Estado do Rio de Janeiro. IFGF 2015 - Índice FIRJAN de gestão fiscal: ano base 2013 - recorte municipal; abrangência nacional. p. 06. Disponível em: http://publicacoes.firjan.org.br/ifgf/2015/files/assets/basic-html/page-1.html. Acesso em: 20 mai. 2018.
} 
(mundo do ser) ou que pretende transformar a realidade (mundo do dever ser) ${ }^{8}$. Logo, a constituição como força instauradora e inaugural ${ }^{9}$, pode reconhecer a ordem econômica vigente (dando-Ihe legitimidade e definindo meios de atuação no segmento econômico), ou partindo da realidade vivenciada, utilizar-se da economia como instrumento de consecução dos objetivos finalísticos do Estado.

A existência de um núcleo dentro do texto constitucional, responsável pela disciplina jurídica da economia, em especial, da conformação dos meios de produção ao sistema econômico é responsável por traçar os parâmetros de atuação dos diversos atores, seja o setor privado ou os entes federados.

O modelo inaugurado na ordem econômica de 1988 traduz essencialmente a intenção do constituinte de respeitar os limites da propriedade privada, da livre iniciativa e a defesa da concorrência, possibilitando assim, um capitalismo em que a produção de riqueza e distribuição da mesma não ocorra como apropriação exclusiva de uma classe, mas se traduza em garantia de existência digna, conforme os ditames da justiça social ${ }^{10}$.

Destaca-se que as discrepâncias entre os processos de desenvolvimento tornam-se evidentes, quando comparados os níveis de desenvolvimento econômico dos municípios das diversas regiões brasileiras ${ }^{11}$. 0 que aponta que a melhora no nível de inserção econômica da população apresentado nas últimas décadas, não atingiu de modo uniforme a federação em sua totalidade.

Portanto, o desenvolvimento deve ser observado como uma mudança estrutural, uma vez que se permite alterar as estruturas econômicas, sociais, políticas, institucionais, com melhoria da produtividade e da renda média dos agentes envolvidos no processo ${ }^{12}$.

Dentre os objetivos da constituição que apresentam sintonia direta com a condução da política econômica, destacam-se a garantia do desenvolvimento nacional, erradicação da pobreza e da marginalização e a busca pela redução das desigualdades sociais e regionais ${ }^{13}$.

Assim, a atuação do Estado (incluindo-se os municípios) como condutor da política econômica se alicerça no texto constitucional, especificamente, no núcleo jurídico denominado constituição econômica. Cabendo ao referido núcleo, dispor das diretrizes a serem empreendidas pelos diversos entes que atuam na federação, com o objetivo de que o processo de desenvolvimento empreendido no Brasil seja uma política de Estado voltada para a coletividade.

\footnotetext{
${ }^{8}$ CYRINO, André. Análise Econômica da Constituição Econômica e Interpretação Institucional. Constituição, Economia e Desenvolvimento: Revista da Academia Brasileira de Direito Constitucional. Curitiba, 2016, vol. 8, n. 15, Jul.- Dez. p. 492-515.

${ }^{9}$ SÁ, Ana Paula Babosa de. O poder Constituinte Originário e sua Limitação Material pelos Tratados Internacionais de Direito Humanos. Disponível em: https://www.epublicacoes.uerj.br/index.php/rfduerj/article/download/1351/1140. Acesso em: 02 jun. 2019.

10 SILVA, José Afonso da. Curso de Direito Constitucional Positivo. 25. ed. São Paulo: Malheiros, 2005. p. 202.

${ }^{11}$ PNUD. Desenvolvimento Humano nas Macrorregiões Brasileiras. Brasília, 2016. Disponível em: https://www.undp.org/content/dam/brazil/docs/IDH/undp-br-macrorregioesbrasileiras-2016.pdf. Acesso em: 07 jun. 2019.

12 SOUZA, Nali de Jesus. Desenvolvimento Econômico. 3. ed. São Paulo: Atlas, 2012. p. 22-23.

${ }^{13}$ BRASIL. Constituição da República Federativa do Brasil de 1988. Disponível em: http://www.planalto.gov.br/ccivil_03/constituicao/constituicaocompilado.htm. Acesso em: 07 jun. 2019.
} 


\section{O PAPEL DO MUNICÍPIO NO DESENVOLVIMENTO LOCAL A PARTIR DA CONSTITUIÇÃO ECONÔMICA DE 1988}

No contexto da ordem econômica inaugurada pela Constituição de 1988, ao Estado (União) foi conferida prima facie a possibilidade de intervir no domínio econômico. Ocorre, que diante das peculiaridades trazidas pela carta de 1988, é possível relacionar também ao município - enquanto gestor de interesses locais - o papel de executor de política intervencionista própria ${ }^{14}$.

A intervenção anteriormente apontada pode ser definida como "qualquer atuação estatal que tenha efeitos diretos sobre a economia, sendo certo que o objetivo perseguido por essa intervenção necessariamente deve ser a efetivação e tutela do interesse público"15, bem como a superação da dependência econômica que se instaura entre municípios e a União.

Para que se possa compreender o papel do município dentro da federação e como o mesmo pode atuar na consecução de um projeto de desenvolvimento local, faz-se necessário elucidar as raízes do atual modelo de federalismo e como o mesmo apresenta percalços em sua estruturação.

O estudo do modelo de federalismo brasileiro e da evolução do papel do município nas constituições, permite a compreensão acerca do fenômeno da dependência (em relação à União) e do engessamento da atuação municipal na estrutura do Estado brasileiro. A partir disso, é possível uma interpretação ampliativa do texto constitucional, em que possam ser vislumbradas alternativas concretas de intervenção ou de incremento da atividade produtiva local.

A forma de Estado adotada no Brasil se consubstancia em um modelo de compartilhamento das competências, onde pode ser reconhecida uma significativa autonomia dos entes que compõe o Estado.

No Brasil, o modelo de federalismo apresenta uma adequação própria à sua realidade, a partir da experiência norte-americana. O federalismo brasileiro consiste em "um movimento de dentro para fora e não de fora para dentro; de força centrífuga e não centrípeta; de origem natural-histórica e não artificial"16.

Nessa perspectiva, o modelo de federalismo brasileiro destoa da realidade do modelo empregado nos Estados Unidos da América - EUA, uma vez que lá empreendeu-se uma agregação, uma construção para os fins do modelo federalista. No Brasil, a estrutura empregada partiu de um movimento desagregador ${ }^{17}$, em que as particularidades regionais e necessidades dos centros locais de poder não foram devidamente observadas.

\footnotetext{
${ }^{14}$ CLARK, Giovani. O município em face do direito econômico. Belo Horizonte: DelRey, 2001.

${ }^{15}$ TOSTA, André Ribeiro. A intervenção do Município no Domínio Econômico e o Regime Jurídico dos Contratos da Petrobrás. São Paulo: PUC/SP, 2014.

${ }^{16}$ MALUF, Sahid. Teoria Geral do Estado. 29. ed. São Paulo: Saraiva, 2009. p. 177.

${ }^{17}$ PACÍfICO, Andrea Pacheco. Os federalismos brasileiro e estadunidense na construção da democracia. Revista de Estudos Internacionais (REI), Vol. 3 (1), 2012. Disponível em: http://www.revistadeestudosinternacionais.com/uepb/index.php/rei/article/viewFile/108/pdf. Acesso em: 10 jun. 2019.
} 
O resultado direto é que embora a constituição de 1891 tenha reproduzido a ideia de federalismo norte-americano, foi ajustado ao Brasil um sistema jurídico-constitucional, que resultou no desencontro (especialmente no que toca às competências e autonomia municipal) entre a constituição escrita e a constituição real do país ${ }^{18}$. Situação esta que se repete nas demais Constituições.

O modelo de federalismo brasileiro apresenta outra particularidade, o reconhecimento da atuação cooperativa. Por esta, os entes (Estados, municípios e a União) devem atuar de modo conjunto, com a finalidade de desempenhar as competências que lhe foram delegadas e harmonizá-las em prol do interesse do Estado como um todo.

\begin{abstract}
Dentre as complexas relações de interdependência entre a União e os entes federados, no federalismo cooperativo devemos distinguir a coordenação da cooperação propriamente dita. A coordenação é, na realidade, um modo de atribuição e exercício conjunto de competências no qual os vários integrantes da Federação possuem certo grau de participação. A vontade das partes é livre e igual, com a manutenção integral de suas competências. $\mathrm{Na}$ cooperação, nem a União, nem qualquer ente federado pode atuar isoladamente, mas todos devem exercer sua competência conjuntamente com os demais. $O$ interesse comum viabiliza a existência de um mecanismo unitário de decisão, no qual participam todos os integrantes da Federação ${ }^{19}$.
\end{abstract}

Gilberto Bercovici assenta que no modelo de cooperação, a atuação dos entes federados se volta para a tomada de decisões conjuntas ${ }^{20}$. Essa tomada de decisões se apoiaria na distribuição das competências e na interdependência entre as mesmas. Ou seja, para cada ente há uma atribuição, que pode ser exercida também por outro (em uma atuação conjunta e interdependente).

Ocorre, que ao longo das constituições brasileiras e de modo prevalente na constituição de 1988, o modelo de federalismo empregado (em suas raízes históricas) conferiu ao ente central (União) inúmeras competências, relegando aos municípios pouco espaço de atuação.

Nesse sentido, destaca Giovani Clark que mesmo tendo força econômica "alguns municípios brasileiros não desfrutam mais de real capacidade para realizar políticas econômicas próprias, em face de um federalismo desvirtuado, que mancha a autonomia de seus entes com uma histórica centralização de poder nas mãos da União"21.

A Constituição Federal de 1988 trouxe inúmeras competências a serem desenvolvidas de modo articulado e cooperado. Contudo, as atribuições não vieram acompanhadas de fomento à gestão local, seja administrativa ou fiscal. De modo que, foram

\footnotetext{
${ }^{18}$ LASSALE, Ferdinand. A essência da constituição. 5. ed. Rio de Janeiro: Lumen Juris, 2000.

${ }^{19}$ BERCOVICI, Gilberto. Desigualdades regionais, Estado e Constituição. São Paulo: Max Limonad, 2003. p. 150 154.

${ }^{20}$ Ibid., p. 146.

${ }^{21}$ CLARK, Giovani. O município em face do direito econômico. Belo Horizonte: DelRey, 2001. p. 85.
} 
criados municípios sem que lhes fossem dadas condições mínimas de desenvolvimento das atividades que lhe são próprias ${ }^{22}$.

A atual Constituição embora textualmente tenha procedido a uma elevação do patamar dos municípios, não disciplinou efetivamente as possibilidades de atuação dos mesmos nas diversas esferas da atividade estatal. Assim, observa-se um quadro de dificuldades que impedem o atendimento das diretrizes constitucionais relacionadas ao desenvolvimento nas três esferas do Estado.

Nessa perspectiva, identifica-se que o processo de urbanização e a crescente complexidade das demandas sociais locais das últimas décadas, assim como o descompasso entre as competências atribuídas aos municípios e suas capacidades; fazem com que o avanço da gestão urbana das cidades se coloque como um desafio para a grande maioria dos municípios brasileiros ${ }^{23}$.

Ainda, a dependência fiscal dos municípios é evidenciada por alguns elementos ou fatores a ela intrínsecos. Inicialmente, a competência arrecadadora plena (maior número de impostos e taxas) é de responsabilidade da União. Poucos são os fatos geradores em que fica incumbido ao município seu lançamento e arrecadação. Ademais, a execução de serviços primordiais é realizada na esfera mais próxima da população, "a despeito de os recursos e suas transferências serem federais ou estaduais na sua origem ou de a execução orçamentária ser consolidada em outras escalas: estadual, regional ou federal (nacional) e exterior" 24 .

A efetiva distribuição de receitas dentro da federação é requisito inerente ao próprio modelo de federalismo. Nesse sentido, oportuno destacar que a importância da distribuição da receita fiscal é patente em um Estado Federal. A autonomia dos entes federados, frente à União, pode ser considerada apenas nominal quando faltam recursos financeiros necessários à sua manutenção ${ }^{25}$.

Estabelece Dalmo de Abreu Dallari:

\begin{abstract}
Aí está um ponto de máxima relevância, que tem sido causa de intensos conflitos entre as diferentes esferas de poder político que compõem a federação brasileira. A União tem evidente superioridade financeira, por força dos próprios dispositivos constitucionais, o que se agrava ainda mais quando o governo federal abusa de suas competências e coloca em plano absolutamente superior seus próprios objetivos, ignorando as exigências constitucionais relacionadas com o federalismo e impondo decisões que representam enorme constrangimento financeiro dos Estados e Municípios e acarretam, na realidade, uma situação de submissão e dependência, anulados a autonomia política implica na organização federativa ${ }^{26}$.
\end{abstract}

\footnotetext{
${ }^{22}$ ROSA, Ivandro Carlos. O processo de emancipação municipal e a urbanização do município de Lajeado - RS. 46 f. Dissertação de Mestrado - Centro Universitário UNIVATES, RS, 2012 . Disponível em: https://www.univates.br/bdu/bitstream/10737/279/1/IvandroRosa.pdf. Acesso em: 11 jun. 2019.

${ }^{23}$ PEREIRA, José Roberto; REZENDE, João Batista. Gestão Pública Municipal. Curitiba: CRV, 2017. p. 112.

${ }^{24}$ MENDES, Constantino Cronemberger. Padrões regionais da despesa pública municipal. Brasília: IPEA, 2015. Disponível em: http://www.ipea.gov.br/portal/images/stories/PDFs/TDs/td_2089.pdf. Acesso em: 10 jun. 2019. ${ }^{25}$ BERCOVICI, Gilberto. Desigualdades regionais, Estado e Constituição. São Paulo: Max Limonad, 2003. p. 160.

${ }^{26}$ DALLARI, Dalmo de Abreu. Implicações do Pacto Federativo. In RAMOS, Dircêo Torrecillas. O federalista atual: teoria do federalismo. Belo Horizonte: Arraes Editores, 2013. p. 589-591.
} 
A situação não se coaduna com o Estado Federal, uma vez que as unidades federadas ficam enfraquecidas, financeira e administrativamente, com a incerta e perigosa dependência da distribuição central ${ }^{27}$.

Assim, em uma perspectiva de dependência fiscal do ente central (União), especialmente, das transferências denominadas Fundo de Participação dos Municípios - FPM, de gestões marcadas pela ineficiência da gestão na consecução de políticas públicas essenciais e ausência de uma política de incentivo da atividade produtiva local, os municípios brasileiros (em sua maioria) agravam ainda mais sua situação de desequilíbrio nas contas públicas, marcadas por déficit na arrecadação e atraso no pagamento de sua folha.

Diante do quadro descrito, a apresentação de medidas criativas por parte da administração pública torna-se um imperativo. Dentre as mesmas destaca-se a intervenção por meio do incentivo às moedas sociais de âmbito local, que repercutem verdadeiramente em um processo de desenvolvimento. Assim, evidencia-se a competência do município para atuar na matéria. Afinal, a melhoria dos índices de desenvolvimento socioeconômico a nível municipal é um objetivo/assunto de interesse local.

Embora não haja a previsão expressa de atuação do município no domínio econômico na Constituição de 1988, mediante intervenção e incentivo à atividade produtiva, a mesma é possível.

Uma interpretação constitucional da ordem econômica desvinculada de pragmatismos, tal como a defendida por Giovani Clark em sua obra o município em face do direito econômico, apresenta um viés possível de planejamento e execução. Pelo mesmo, os princípios e regras norteadores da atividade econômica, podem ser aplicados aos municípios, cabendo a estes - enquanto gestores de interesses locais - atuarem no domínio econômico com o intento de desenvolver a economia local e ao mesmo tempo fomentar o desenvolvimento nacional, uma vez que a federação deve funcionar como um todo. Referida possibilidade se revela quando o município pode atuar na esfera da economia local com o incentivo à criação de moedas sociais. É o que se discutirá na próxima seção.

\section{INTERVENÇÃO DO MUNICÍPIO NO DOMÍNIO ECONÔMICO E AS MOEDAS SOCIAIS}

O município pode intervir no domínio econômico, ao implementar dentro dos limites de sua competência, políticas econômicas locais, de fomento à atividade produtiva. A possibilidade de intervenção é uma resposta a um processo histórico de limitação da autonomia municipal, bem como a dependência financeira enfrentada pelas municipalidades.

Atuar dentro das especificidades locais é uma alternativa concreta e se coaduna com todos os princípios sob as quais se erige o Estado brasileiro. O Estado hoje deve ultrapassar os limites convencionais de sua atuação, servindo como indutor de transformações, de uma verdadeira mudança na perspectiva mantida entre a comunidade, o setor privado e o setor público.

${ }^{27}$ CARVALHO PINTO, Carlos Alberto. Apud BERCOVICI, Gilberto. Desigualdades regionais, Estado e Constituição. São Paulo: Max Limonad, 2003. p. 161. 
Ante o exposto, observa-se a possibilidade de o município intervir no domínio econômico, a partir de uma interpretação lógica do texto constitucional, além de se constatar a competência municipal para legislar sobre matéria de direito econômico no tocante aos temas de seu interesse. Nessa linha, destaca-se a possibilidade de instituição das moedas sociais pelos municípios ao passo em que se desenvolve uma perspectiva jurídica e econômica que as afirme como uma das políticas de desenvolvimento local.

$\mathrm{Na}$ interpretação desenvolvida no presente trabalho, a capacidade interventiva pode ser estendida aos municípios, enquanto entes integrantes da organização administrativa brasileira e detentores de competência para legislar sobre direito econômico; não se afastando dos limites impostos na ordem jurídica, em especial na Constituição Federal de 1988. Destaca-se que as "intervenções econômicas realizadas pelo Estado, incluindo-se o município, devem balizar-se, logicamente, nos ditames da ordem jurídica, trazendo sempre as marcas da racionalidade, coerência e participação social"28.

Assim, os princípios constitucionais que regem a ordem econômica evidenciam que o poder constituinte originário levou em conta e foi influenciado pela concepção de constituição dirigente e com ela assumiu o entendimento de que o crescimento econômico deve estar voltado para o desenvolvimento.

Exige-se, portanto, uma atuação conjunta de todos os entes do Estado federal, que de modo uníssono devem perseguir os objetivos estabelecidos na constituição. Nesse contexto é flagrante o papel de direção e de indução do desenvolvimento econômico que cabe ao Estado e ao município ${ }^{29}$.

Nessa perspectiva de indução do desenvolvimento, as moedas sociais ou locais podem ser conceituadas como instrumentos paralelos à moeda oficial brasileira - o real - que têm oferecido alternativa importante ao desenvolvimento econômico e social de comunidades carentes ${ }^{30}$. Podendo ainda serem definidas como uma das ferramentas de atuação dos bancos comunitários na promoção do desenvolvimento de territórios de baixa renda, a partir do fomento à criação de redes locais de produção e consumo ${ }^{31}$.

Oportuno salientar que, a instituição de moedas no plano nacional é competência da União, consoante o previsto no artigo 21 da Constituição Federal. Entretanto consagrou-se nos últimos anos, a partir da experiência exitosa do Banco Palmas a instituição de moedas sociais ou locais pelo poder público municipal.

Atualmente, o Brasil convive com uma realidade na qual existem diversos meios utilizados como circulante monetário (moeda). Como anteriormente mencionado a competência de emissão de moeda é da União, que assim pode atuar defensivamente (proibindo a emissão de instrumentos semelhantes, o controle da sua emissão, ou mesmo regular e restringir a sua circulação).

\footnotetext{
${ }^{28}$ CLARK, Giovani. O município em face do direito econômico. Belo Horizonte: DelRey, 2001. p. 43.

${ }^{29}$ SOUZA, Washington Peluso Albino de; CAMARGO, Ricardo Antônio Lucas. TORELLY, Paulo Peretti. Constituição Econômica e Pacto Federativo. Porto Alegre: Núria Fabris, 2015. p.120-125.

${ }^{30}$ FOBE, Nicole. A regulação brasileira das moedas sociais. Disponível em: http://www.publicadireito.com.br/artigos/?cod=066763a699fbe4dc. Acesso em: 21 jun. 2018.

31 INSTITUTO BANCO PALMAS. Instituto Palmas de Desenvolvimento e Socioeconomia Solidária. Termo de Referência dos bancos comunitários de desenvolvimento. Disponível em: http://www.institutobancopalmas.org/termo-de-referencia-dos-bancos-comunitarios-de-desenvolvimento/. Acesso em: 10 jun. 2019.
} 
Contudo, o que a experiência de inúmeros bancos comunitários apresenta são os impactos socioeconômicos que as moedas de âmbito local têm trazido. São benefícios como o incentivo à circulação da riqueza, o investimento em setores deficitários da economia da região, criação de mecanismos de promoção do desenvolvimento humano e econômico, aumento do poder de compra e inclusão de indivíduos excluídos do processo econômico via concessão de micro empréstimos de caráter produtivo ou mesmo para o consumo ${ }^{32}$.

A disciplina da constituição de $1988^{33}$, no tocante a distribuição das competências entre os entes, confere à União a competência sobre a emissão de moeda (art. 21, VII, CRFB), cabendo ao Banco Central exercê-la com exclusividade nos termos do artigo 164 da CRFB e dos instrumentos normativos editados pelo congresso nacional, como é o caso da lei $13.416 / 2017^{34}$.

É importante deixar claro que, na teoria econômica moderna, "a moeda de curso legal nunca é definida unicamente como dinheiro (papel-moeda e moedas metálicas produzidas e emitidas pelo Banco Central em nome da União)"35, porque tanto o dinheiro como os depósitos em contas correntes fazem o mesmo: pagam bens e serviços.

Entre as várias moedas tidas como ativos circulantes, e submetidas à fiscalização e controle do Banco Central estão as denominadas moedas oficiais, exemplificadas pela moeda fiduciária (emitida pelo Bacen, não lastreada e monopolizada pelo Estado) e as moedas bancárias (invisível que não tem existência física, correspondendo aos lançamentos de débito e crédito nas contas correntes) ${ }^{36}$.

Por seu turno, as moedas sociais de circulação local, restritas a espaços comunitários previamente definidos e estabelecidos nas economias locais, não são incluídas entre os ativos definidos nos agregados monetários que são controlados pelo Banco Central ${ }^{37}$.

Assim, inexiste fiscalização ou intervenção das moedas sociais por parte do Banco Central, uma vez que as mesmas apresentam particularidades próprias, por dois motivos:

Primeiro, porque o poder emissor das moedas sociais não se agasalha e
hospeda em instituições financeiras depositárias. Ou seja, não envolve, em
geral, reservas prévias de recursos monetários captados do público
destinados ao financiamento de terceiros. Segundo, pela sua reduzida
dimensão tanto em termos de volume de transações como de valores
individuais e agregados das transações que não ultrapassa percentual

32 OLIVEIRA, Marcos Prestes de. Moedas sociais como mais um instrumento para potencializar o desenvolvimento da economia local. Monografia (Curso de Bacharelado em Direito). Unijuí: ljuí, 2012. Disponível em: http://bibliodigital.unijui.edu.br:8080/xmlui/handle/123456789/1002. Acesso em: 17 mai. 2018.

${ }^{33}$ BRASIL. Constituição da República Federativa do Brasil de 1988. Vade Mecum JusPodivm OAB. Salvador: JusPodivm, 2019. p. 40.

${ }^{34}$ Autoriza o Banco Central do Brasil a adquirir papel-moeda e moeda metálica fabricados fora do País por fornecedor estrangeiro.

${ }^{35}$ FREIRE, Marusa Vasconcelos. Moedas Sociais: contributo em prol de um marco legal e regulatório para as moedas sociais circulantes locais no Brasil. 374 f. Tese (Doutorado em Direito) - Universidade de Brasília, Brasília, 2011. Disponível em: http://repositorio.unb.br/bitstream/10482/9485/1/2011_MarusaVasconcelosFreire.pdf Acesso em: 08 mar. 2019.

${ }^{36}$ Ibid., p. 49.

37 Ibid., p. 56. 
mínimo, que certamente fica bem abaixo de $1 \%$ a $4 \%$, representado pelo meio circulante (papel-moeda e moedas metálicas do poder público) ${ }^{38}$.

Embora a emissão de moeda seja de competência exclusiva da União, através do Banco Central do Brasil, o controle dos instrumentos a ela relacionados (emissão, fiscalizações e regulamentação) não se aplicam às moedas sociais.

Destaca-se que a natureza das moedas sociais é objeto de grande discussão, uma vez que ainda surgem inúmeras dúvidas acerca da viabilidade jurídica das mesmas, especialmente, no que toca a competência para sua emissão.

$\mathrm{Na}$ tentativa de afastar a celeuma quanto a matéria das moedas sociais, o Banco Central do Brasil, através da nota técnica PGBC - 387/2011, de 10 de setembro de 2011, consolidou inúmeras manifestações anteriores de sua procuradoria. Na referida nota técnica, as moedas sociais foram consideradas como um bônus, ou seja, a moeda social não é circulante efetivo. Após a troca pelos munícipes, podem ser adquiridos produtos e serviços locais com descontos. Por outro lado, os comerciantes quando necessitarem da moeda oficial (o real), efetuarão a respectiva troca junto ao banco comunitário local ${ }^{39}$.

A nota técnica aponta também que a "circulação da moeda social é livre no comércio local e, geralmente, quem compra com a moeda social recebe um desconto patrocinado pelos comerciantes ${ }^{\prime 40}$ com o intuito de fomentar a economia.

Ainda sobre as moedas sociais, é importante destacar que "ninguém pode ser obrigado a aceitá-la ou participar de um sistema de moedas sociais, pois elas não têm curso forçado, nem poder liberatório assegurado por lei"41.

Para concluir a discussão de que a política de instituição ou incentivo às moedas sociais não vai de encontro ao ordenamento nacional, a nota técnica 387/2011 arremata que:

\begin{abstract}
A instituição de moedas sociais está associada a políticas públicas de combate à pobreza e de promoção do desenvolvimento local, apoiadas pela Secretaria Nacional de Economia Solidária do Ministério do Trabalho e Emprego, pelo Ministério de Desenvolvimento Social e pelo Ministério do Desenvolvimento Agrário. Por esse motivo, desde que as regras constitutivas dos contratos (formais ou informais) nos programas de finanças solidárias com base em bancos comunitários e fundos rotativos não violem as disposições estabelecidas no ordenamento jurídico vigente (especialmente no que se refere à finalidade do uso de moedas sociais circulantes locais, à imagem das moedas sociais e aos limites estabelecidos pela Lei de Usura ou ao regime de juros específico, quando o programa estiver relacionado a algum projeto de microcrédito do banco comunitário), a emissão de moedas sociais circulantes locais não pode ser considerada, por si só, como uma prática ilegal ${ }^{42}$.
\end{abstract}

\footnotetext{
38 Ibid., p. 76.

39 BACEN. Banco Central do Brasil. Nota técnica 387/2011, de 10 de setembro de 2011. Nota técnica sobre finanças solidárias. Anais /I Fórum Banco Central sobre inclusão financeira, Brasília, 2010. Disponível em: https://www.bcb.gov.br/pre/microfinancas/anais_II_forum_inclusao_financeira.pdf. Acesso em: 10 jun. 2019.

40 lbid., p. 146.

41 Ibid., p. 147.

42 Ibid., p. 150.
} 
Portanto, a instituição das moedas sociais pode ser objeto de política econômica local na modalidade de incentivo, sem que as mesmas se confundam com as moedas de curso oficial, no caso brasileiro, o real.

Ainda que ao município não tenha sido atribuída a competência para a emissão da moeda oficial (na perspectiva constitucional do art. 21, VII), a interpretação lógica da constituição permite inferir que ao tratar de direito econômico (matéria que pode ser regulada pelo município), o incentivo às moedas sociais pode ser instrumento de intervenção municipal. A política discutida se enquadra dentro da economia (economia solidária ${ }^{43}$ ), e, por conseguinte, dentro do direito econômico ${ }^{44}$. Ademais, não se pode ignorar a importante contribuição socioeconômica das supracitadas moedas.

A moeda local complementa a renda e permite o acesso imediato por parte dos consumidores a produtos básicos. Possui uma função redistributiva e de ativação da economia local; além de funcionar como meio capaz de incentivar e fortalecer o capital social da localidade, trazendo consigo a percepção de desenvolvimento local ${ }^{45}$.

O primeiro banco comunitário do Brasil, o Banco Palmas, surge em um bairro da periferia de Fortaleza $-\mathrm{CE}^{46}$. A história do Banco Palmas está alicerçada por uma construção longa e coletiva dos munícipes, em busca de condições dignas de moradia. Essa área, chamada de Conjunto Palmeiras, era um grande alagado distante do centro, que não tinha fornecimento de luz, água ou qualquer condição de urbanização ${ }^{47}$.

O Banco Palmas surge inicialmente, com a proposta de superar uma problemática definida, notadamente, o problema habitacional na área do conjunto Palmeiras. Contudo, a experiência é tão exitosa que as atividades da associação vinculada ao conjunto Palmeiras (Asmoconp), ampliam as respostas aos problemas locais. Destaca Adriano Borges que

\footnotetext{
${ }^{43}$ Segundo Paul Singer a economia solidária propõe outra organização da produção, à base da propriedade social dos meios de produção. Isso não quer dizer a estatização desta propriedade, mas a sua repartição entre todos os que participam da produção social. O desenvolvimento solidário não propõe a abolição dos mercados, que devem continuar a funcionar, mas sim a sujeição dos mesmos a normas e controles, para que ninguém seja excluído da economia contra a sua vontade (SINGER, Paul. Desenvolvimento capitalista e desenvolvimento solidário. Estudos Avançados 18, 2004).

${ }^{44}$ SOUSA, Thalyta Taumaturgo de. A economia solidária como meio para o desenvolvimento sustentável - o caso do banco Palmas. 67 f. Dissertação (Mestrado em economia e meio ambiente) - Universidade do Porto, Porto, 2011. Disponível em: http://base.socioeco.org/docs/a_economia_solid_ria_como_meio_para_o_desenvolvimento_sustent_vel_caso_do_banco_palmas-1.pdf. Acesso em: 13 jun. 2019.

${ }^{45}$ PEREIRA, Wallace Marcelino; CROCCO, Marco Aurélio. Inclusão financeira a partir de moedas locais: um estudo exploratório do banco palmas, Fortaleza - CE. Anais do I circuito de debates acadêmicos, CODE 2011. Disponível em: http://www.ipea.gov.br/code2011/chamada2011/pdf/area7/area7-artigo30.pdf. Acesso em: 12 jun. 2019. ${ }^{46}$ FRIZON, Nayana; CARVALHO, Hilano José Rocha de; ZANIN, Maria. Bancos Comunitários de Desenvolvimento: tendências e lacunas nas publicações brasileiras. Revista de Desenvolvimento Econômico - RDE - Ano XVII - Edição especial - Dezembro de 2015 Salvador, BA - p. 699 - 719 . Disponível em: http://revistas.unifacs.br/index.php/rde/article/download/4005/2854. Acesso em: 10 jun. 2019.

47 MATURANA, André Vinícios Koltermann; COSTA, Luiza Gaiger da; KOHLER, Romualdo. Moeda social como instrumento de desenvolvimento local: um levantamento das práticas realizadas no território nacional. Anais do XXVI Seminário de Iniciação Científica da Unijuí, SC, 2018. Disponível em: https://publicacoeseventos.unijui.edu.br/index.php/slaedr/article/view/10536. Acesso em: 10 jun. 2019.
} 
com o Conjunto Palmeiras urbanizado, a Asmoconp e seus associados definiram que o desenvolvimento econômico dos moradores era então o maior desafio do bairro, e motivação para criar um projeto que buscasse conceder pequenos créditos e fomentar a economia local - o Banco Palmas. A experiência se desenvolve, consegue captar um volume considerável de recursos para conceder crédito, cria empreendimentos de economia solidária, campanhas para incentivar o consumo de produtos do bairro e uma moeda social, o Palmas (P\$). Hoje se trata de uma experiência que engloba a Associação de Bairro, sua história, o Banco Palmas propriamente dito, e o Instituto Palmas, uma organização criada com o objetivo de reaplicar a tecnologia dos bancos comunitários e desenvolver formas de apoio a essas experiências $^{48}$.

Dentre as inúmeras iniciativas do Banco Palmas, está a criação da moeda Palma, a primeira moeda social brasileira e que com o início das atividades do Instituto Palmas, passou a servir de modelo para as ações de fomento à economia local de inúmeros municípios.

Esclarece Arilsom Martins que:

\begin{abstract}
a moeda (Palma) é um dinheiro alternativo, de uso exclusivo no Banco Palmas, que circula somente no bairro, paralelamente à moeda oficial brasileira. Quem compra com palmas nas lojas do comércio local tem um desconto que varia de $2 \%$ a $10 \%$. A ideia da moeda surgiu da necessidade de fazer circular a riqueza gerada dentro do próprio bairro. Cada Palma equivale a $\mathrm{R} \$ 1,00$ e os moradores conseguem a moeda com o próprio trabalho ou fazendo empréstimo no Banco. O empréstimo funciona num sistema de crédito e juros baixos ( $2 \%$ a $4 \%$ a.m.), porém evolutivos, de modo que os que dispõem de mais renda pagam mais, como forma de subsidiar o empréstimo dos menos favorecidos ${ }^{49}$.
\end{abstract}

Cabe destacar que, a iniciativa do Banco Palmas, influenciou diretamente a criação de inúmeras outras moedas sociais no Brasil, dentre as quais: o Cocal (São João do Arraial PI), Gostoso (São Miguel do Gostoso - RN), a Opala (Pedro II - PI), a Mumbuca (Maricá - RJ), Concha (Matarandiba - BA), Santana (Santana do Acaraú - CE) e Palmeiras (Palmácia - CE) ${ }^{50}$.

Assim, é possível reconhecer que as moedas sociais são produto de atuação comunitária, formadas a partir de um vínculo jurídico estabelecido pela própria comunidade, "o que pressupõe uma participação democrática das pessoas em torno de uma organização da sociedade civil ou de outros grupos informais, em geral, sem fins lucrativos, formando circuitos econômicos comunitários" ${ }^{11}$.

\footnotetext{
48 MORAIS, Leandro; BORGES, Adriano. (orgs.) Novos Paradigmas de produção e consumo: experiências inovadoras. São Paulo: Instituto Polis, 2010.

${ }^{49}$ NASCIMENTO, Arilsom Martins. Moeda Palma e o desenvolvimento sustentável do Conjunto Palmeiras através da economia solidária. 131 f. Dissertação (Mestrado em Economia) - Universidade Federal do Ceará, Fortaleza, 2011. Disponível em: http://www.repositorio.ufc.br/handle/riufc/6213 Acesso em: 12 jun. 2019.

${ }^{50}$ SILVA JÚNIOR, Jeová Torres; GONÇALVES, Sarah Maria da Silva; CALOU, Angela Lima. Os Bancos Comunitários como Instrumento de Desenvolvimento Socioeconômico de Territórios: Investigando as Singularidades destas Experiências de Finanças Solidárias. Anais do XXXI Encontro da ANPAD, Rio de Janeiro, 2007. Disponível em:http://www.anpad.org.br/admin/pdf/APS-C2557.pdf. Acesso em: 12 jun. 2019.

${ }^{51}$ FREIRE, Op. cit., p. 146.
} 
Embora, em um primeiro momento, possa ser reconhecida à comunidade a iniciativa pela criação e implementação das moedas sociais, ressalta-se que o município enquanto parcela local do poder estatal, tem atuação decisiva no sentido de fomentar, aprimorar e regulamentar as moedas sociais. Podendo ainda, valer-se de instrumentos normativos próprios para consolidar sua participação nesse processo de desenvolvimento local.

Dentre as inúmeras moedas sociais existentes no Brasil, dois casos particulares podem ser tomados como exemplos de intervenção municipal. Onde os municípios agiram como verdadeiros "empreendedores", ao disporem de leis para conceber, implementar e desenvolver as moedas sociais em seus respectivos espaços geográficos: os municípios de São João do Arraial - PI e Maricá -RJ.

No município de São João do Arraial - PI, através da lei municipal no 114/2007 foi criado o Fundo Municipal de Microcrédito e Apoio à Economia Solidária - FUMAES, instituído o Conselho Gestor do FUMAES e destinados recursos orçamentários do município para o financiamento do fundo.

No caso de São João do Arraial, a economia do município vivia uma relação de dependência não só no quesito bancário (financiamentos e serviços), mas também no quesito consumo. O comércio local estagnava-se cada vez mais com a saída de dinheiro do município para os municípios vizinhos. Para completar essa situação de dependência, a capacidade de produção do município era reduzida e sem condições de atender às necessidades variadas da população $0^{52}$.

Por iniciativa do prefeito municipal, foi formada uma equipe para realizar o mapeamento do município, com o objetivo de identificar quais as necessidades, o que era produzido localmente e quais os potenciais de produção. $O$ objetivo era investir em ações de fomento que propiciassem o crescimento do município ${ }^{53}$.

A partir de uma sistemática de planejamento voltado para as especificidades locais, foi editada a lei no 114/2007, e implementada uma série de ações voltadas para a dinamização da economia local.

O objetivo primordial do fundo criado através da supracitada lei seria o de centralizar e gerenciar recursos orçamentários para os programas destinados a implementar políticas de geração de trabalho e renda direcionadas à população de menor renda ${ }^{54}$.

A atividade indutora do município se revela através da alocação de recursos para uma atividade econômica, que passaria a ser política econômica municipal, qual seja, o fortalecimento do crédito e da moeda social implementada no território, com a finalidade de gerar empregos e distribuir renda, uma vez que a moeda social contribui para que os produtos locais sejam valorizados, deixando a riqueza produzida no próprio município.

Ao longo da lei instituidora do fundo municipal de apoio à economia solidária, houve a preocupação em evidenciar os meios de recursos de garantia das atividades instituídas pelo mesmo, notadamente, os recursos delineados nos artigos 3으 e 4ㅇ da lei 114/2007.

\footnotetext{
52 PACHECO, Op. cit., p. 149.

53 Ibid., p. 150.

${ }^{54}$ SÃO JOÃO DO ARRAIAL. Prefeitura Municipal de São João do Arraial - PI. Lei Municipal 114 de 2007. Artigo 2 은 da lei 114/2007 de São João do Arraial - PI.
} 
Pelo que se depreende do instrumento legal aprovado pelo poder legislativo e sancionado pelo Prefeito Municipal, as atividades vinculadas à moeda social (cocal), passam a ter participação direta do poder público municipal, que dentro de sua competência para intervir em matéria econômica (nos limites de seus interesses) concebe e estrutura toda uma rede de fomento à economia da municipalidade.

Na mesma perspectiva, o poder público municipal de Maricá -RJ, apoiado pelo Instituto Palmas edita a lei no 2448 de 2013. A partir da mesma, ficou instituído o programa de economia solidária, combate à pobreza e desenvolvimento econômico e social do município de Maricá, como forma de combater as desigualdades sociais, fomentar o desenvolvimento econômico e social das comunidades e estabelecer meios de erradicação da pobreza e a geração de emprego e renda para as camadas mais carentes do município ${ }^{55}$, através de inúmeras ações dentre as quais a de fortalecer a moeda social Mumbuca.

Além de destinar recursos, a lei no 2.448 de junho de 2013 também definiu a forma como as atividades de economia solidária seriam desenvolvidas, como deveria ocorrer a política de incentivo à moeda Mumbuca (art. 1ㅇ) e de que modo o poder púbico deveria atuar junto à comunidade na consecução dos objetivos de erradicação da pobreza e fortalecimento da economia local (arts. 2으, 4으, 7으, 11 e 15).

A experiência brasileira demonstra que no sistema jurídico existe alguma possibilidade de criação e implantação das moedas sociais, sem desrespeitar a legislação específica sobre a moeda de curso legal (moedas oficiais) ${ }^{56}$, sendo aquelas um veículo de incentivo à uma economia própria, em que se produz e se consome localmente.

Portanto, as moedas sociais podem ser implementadas através de instrumentos legais de âmbito local, que não se restringem à instituição das mesmas. As leis anteriormente referidas demonstram que o poder público municipal pode desempenhar um papel fundamental de fomento à economia local, alicerçado em uma política complexa que envolve inúmeros sujeitos e cuja atuação é voltada para retirar o ente municipal da inércia econômica.

\section{- CONSIDERAÇÕES FINAIS}

A ordem jurídica inaugurada pela Constituição Federal de 1988, trouxe entre seus inúmeros princípios, a responsabilidade em se construir uma sociedade justa, pautada pela redução das desigualdades e marginalização.

O quadro dos municípios no atual contexto da federação é marcado pela pouca obtenção de receita, pela dependência das transferências de recursos, pela exclusão financeira e pela pouca iniciativa de gestores em estabelecer políticas de diversificação da base econômica.

Embora o modelo de federalismo brasileiro tenha sido substancialmente afetado por um conjunto de fatores - históricos, fiscais, econômicos - concedendo à União maior campo

\footnotetext{
${ }^{55}$ MARICÁ. Prefeitura Municipal de Maricá - RJ. Lei 2.448 de 26 de junho de 2013. Artigo 1o da lei 2.448 de 26 de junho de 2013.

${ }^{56}$ FREIRE, Op. cit., p. 338.
} 
de atuação dentro da economia brasileira, os municípios enquanto gestores de interesses locais são responsáveis também por atuar em sua economia, desenvolvendo-a.

Uma interpretação lógica da constituição econômica permite conceber o desenvolvimento como um objetivo comum a ser perseguido por todos os entes. É certo afirmar que os municípios têm um papel fundamental nesse contexto. Estão na posição de maior proximidade da população e desempenham um grande leque de atribuições. Desse modo, urge necessária a defesa de uma maior participação dos municípios em suas economias com a finalidade de incremento das atividades produtivas e melhoria nas condições socioeconômicas.

Nessa perspectiva de ampliação das possibilidades de o município agir na esfera econômica, evidenciam-se as moedas sociais. As mesmas são importante instrumento de dinamização da economia. Promovem a inclusão das pessoas, fomentam o crédito e o consumo, ao tempo em que diversificam a base da produção local. Partindo da literatura pertinente, é possível afirmar que o município pode intervir no domínio econômico e se utilizar das moedas sociais como um desses instrumentos.

No contexto dessa atuação, o município pode atuar em três segmentos: articulação, incentivo e regulamentação. Articula como responsável pela aproximação entre as instituições, comunidade e as experiências exitosas de outros municípios. Incentiva ao atuar com uma política econômica de identificação das potencialidades e perspectivas de incremento da atividade produtiva. E regulamenta quando se vale de instrumentos legais para disciplinar o papel das moedas sociais em âmbito local e ao mesmo tempo dispor dos meios necessários à implementação das mesmas.

Logo, a atuação do município em sua economia com a finalidade de desenvolvê-la, representa o atendimento das diretrizes da constituição econômica. Não há qualquer descompasso na atuação municipal no tocante à matéria, em especial, quando se utiliza das moedas sociais como instrumento de sua política econômica. O que faz, portanto, é política de fomento à economia, voltada para fins de desenvolvimento socioeconômico.

\section{REFERÊNCIAS}

ANDRADE, Mário Cesar da Silva. Dependência financeira dos municípios brasileiros: entre o federalismo e a crise econômica. Revista Espaço Acadêmico - n. 185 - outubro/2016.

BACEN. Banco Central do Brasil. Banco Central do Brasil: fique por dentro. 4. ed. Brasília, BACEN, 2008.2 Disponível em: https://www.bcb.gov.br/htms/sobre/bcuniversidade/cartilhaBancoCentral.pdf. Acesso em: 13 jun. 2019.

- Banco Central do Brasil. 2014. Disponível em: http://www.bcb.gov.br/Nor/relincfiin/RIF2011.pdf. Acesso em: 13 jun. 2019.

. Banco Central do Brasil. Nota técnica 387/2011, de 1ㅇ de setembro de 2011. Nota técnica sobre finanças solidárias. Anais II Fórum Banco Central sobre inclusão financeira, Brasília, 2010.

Disponível

em: 
https://www.bcb.gov.br/pre/microfinancas/anais_II_forum_inclusao_financeira.pdf. Acesso em: 10 jun. 2019.

BERCOVICI, Gilberto. Dilemas do Estado Federal Brasileiro. Porto Alegre: Livraria do Advogado, 2004.

. Desigualdades regionais, Estado e Constituição. São Paulo: Max Limonad, 2003.

CARVALHO PINTO, Carlos Alberto. Apud BERCOVICI, Gilberto. Desigualdades regionais, Estado e Constituição. São Paulo: Max Limonad, 2003.

CLARK, Giovani. O município em face do direito econômico. Belo Horizonte: DelRey, 2001.

CROCCO, Marco Aurélio; SANTOS, Fabiana; FIGUEIREDO, Ana. Exclusão financeira no Brasil: uma análise regional exploratória. Revista de Economia Política, vol. 33, n. 3 (132), p. 505-526, julho-setembro/2013.

Disponível

em:

http://www.scielo.br/scielo.php?script=sci_arttext\&pid=S0101-31572013000300008. Acesso em: 13 jun. 2019.

CYRINO, André. Análise Econômica da Constituição Econômica e Interpretação Institucional. Constituição, Economia e Desenvolvimento: Revista da Academia Brasileira de Direito Constitucional. Curitiba, 2016, vol. 8, n. 15, Jul.-Dez.

DALLARI, Dalmo de Abreu. Implicações do Pacto Federativo. In RAMOS, Dircêo Torrecillas. $O$ federalista atual: teoria do federalismo. Belo Horizonte: Arraes Editores, 2013.

FERRAZ, Luciano. Município e Federalismo. In: NASCIMENTO, C.V. et al (org.) Tratado de Direito Municipal. Belo Horizonte: Fórum, 2018.

FIRJAN - Federação das Indústrias do Estado do Rio de Janeiro. IFGF 2015 - Índice FIRJAN de gestão fiscal: ano base 2013 - recorte municipal; abrangência nacional. Disponível em: http://publicacoes.firjan.org.br/ifgf/2015/files/assets/basic-html/page-1.html. Acesso em: 20 mai. 2018.

FOBE, Nicole. A regulação brasileira das moedas sociais. Disponível em: http://www.publicadireito.com.br/artigos/?cod=066763a699fbe4dc. Acesso em: 21 jun. 2018.

FREIRE, Marusa Vasconcelos. Moedas Sociais: contributo em prol de um marco legal $e$ regulatório para as moedas sociais circulantes locais no Brasil. $374 \mathrm{f}$. Tese (Doutorado em Direito) - Universidade de Brasília, Brasília, 2011. Disponível em: http://repositorio.unb.br/bitstream/10482/9485/1/2011_MarusaVasconcelosFreire.pdf. Acesso em: 08 mar. 2019.

FRIZON, Nayana; CARVALHO, Hilano José Rocha de; ZANIN, Maria. Bancos Comunitários de Desenvolvimento: tendências e lacunas nas publicações brasileiras. Revista de Desenvolvimento Econômico - RDE - Ano XVII - Edição especial - Dezembro de 2015 Salvador, BA $\quad-\quad$ p. $\quad 699 \quad$ - $\quad 6719 . \quad 7$ Disponível em: http://revistas.unifacs.br/index.php/rde/article/download/4005/2854. Acesso em: 10 jun. 2019.

INSTITUTO BANCO PALMAS. Instituto Palmas de Desenvolvimento e Socioeconomia Solidária. Termo de Referência dos bancos comunitários de desenvolvimento. Disponível em: 
http://www.institutobancopalmas.org/termo-de-referencia-dos-bancos-comunitarios-dedesenvolvimento/. Acesso em: 10 jun. 2019.

LASSALE, Ferdinand. A essência da constituição. 5. ed. Rio de Janeiro: Lumen Juris, 2000.

MALUF, Sahid. Teoria Geral do Estado. 29. ed. São Paulo: Saraiva, 2009.

MARICÁ. Prefeitura Municipal de Maricá - RJ. Lei 2.448 de 26 de junho de 2013.

MATURANA, André Vinícios Koltermann; COSTA, Luiza Gaiger da; KOHLER, Romualdo. Moeda social como instrumento de desenvolvimento local: um levantamento das práticas realizadas no território nacional. Anais do XXVI Seminário de Iniciação Científica da Unijuí, SC, 2018. Disponível

em: https://publicacoeseventos.unijui.edu.br/index.php/slaedr/article/view/10536. Acesso em: 10 jun. 2019.

MENDES, Constantino Cronemberger. Padrões regionais da despesa pública municipal. Brasilia: $\quad 2015.2$ Disponível em: http://www.ipea.gov.br/portal/images/stories/PDFs/TDs/td_2089.pdf. Acesso em 10 jun. 2019.

MENDES, Gilmar Ferreira; BRANCO, Paulo Gustavo Gonet. Curso de Direito Constitucional. 7. ed. São Paulo: Saraiva, 2012.

MORAIS, Leandro; BORGES, Adriano. (orgs.) Novos Paradigmas de produção e consumo: experiências inovadoras. São Paulo: Instituto Polis, 2010.

NASCIMENTO, Arilsom Martins. Moeda Palma e o desenvolvimento sustentável do Conjunto Palmeiras através da economia solidária. 131 f. Dissertação (Mestrado em Economia) Universidade Federal do Ceará, Fortaleza, 2011. Disponível em: http://www.repositorio.ufc.br/handle/riufc/6213 Acesso em: 12 jun. 2019.

OLIVEIRA, Marcos Prestes de. Moedas sociais como mais um instrumento para potencializar o desenvolvimento da economia local. Monografia (Curso de Bacharelado em Direito). Unijuí: ljuí, $2012 . \quad$ Disponível em: http://bibliodigital.unijui.edu.br:8080/xmlui/handle/123456789/1002. Acesso em: 17 mai. 2018.

PACÍFICO, Andrea Pacheco. Os federalismos brasileiro e estadunidense na construção da democracia. Revista de Estudos Internacionais (REI), Vol. 3 (1), 2012. Disponível em: http://www.revistadeestudosinternacionais.com/uepb/index.php/rei/article/viewFile/108/p df. Acesso em: 10 jun. 2019.

PACHECO, Françoise Wilhelm Fontenele e V. A inserção social dos cocais no município de São João do Arraial - PI. 301 f. Tese (Doutorado em Geografia) - Universidade Estadual Paulista, Rio Claro, 2016. Disponível em: http://bdtd.ibict.br/vufind/Record/UNSP_68bda42db7152806179a994adc77d94f. Acesso em: 13 jan 2019.

PEREIRA, José Roberto; REZENDE, João Batista. Gestão Pública Municipal. Curitiba: CRV, 2017. PEREIRA, Wallace Marcelino; CROCCO, Marco Aurélio. Inclusão financeira a partir de moedas locais: um estudo exploratório do banco palmas, Fortaleza - CE. Anais do I circuito de debates acadêmicos,

CODE

2011.

Disponível

em: 
http://www.ipea.gov.br/code2011/chamada2011/pdf/area7/area7-artigo30.pdf. Acesso em: 12 jun. 2019.

PNUD. Desenvolvimento Humano nas Macrorregiões Brasileiras. Brasília, 2016. Disponível em: https://www.undp.org/content/dam/brazil/docs/IDH/undp-br-macrorregioesbrasileiras2016.pdf. Acesso em: 07 jun. 2019.

ROSA, Ivandro Carlos. O processo de emancipação municipal e a urbanização do município de Lajeado - RS. 46 f. Dissertação de Mestrado - Centro Universitário UNIVATES, RS, 2012. Disponível em: https://www.univates.br/bdu/bitstream/10737/279/1/lvandroRosa.pdf. Acesso em: 11 jun. 2019.

SÁ, Ana Paula Babosa de. O poder Constituinte Originário e sua Limitação Material pelos Tratados Internacionais de Direito Humanos. Disponível em: https://www.epublicacoes.uerj.br/index.php/rfduerj/article/download/1351/1140. Acesso em: 02 jun. 2019.

SÃO JOÃO DO ARRAIAL. Prefeitura Municipal de São João do Arraial - PI. Lei Municipal 114 de 2007.

SILVA, José Afonso da. Curso de Direito Constitucional Positivo. 25. ed. São Paulo: Malheiros, 2005.

SOUSA, Thalyta Taumaturgo de. A economia solidária como meio para o desenvolvimento sustentável - o caso do banco Palmas. 67 f. Dissertação (Mestrado em economia e meio ambiente) - Universidade do Porto, Porto, 2011. Disponível em: http://base.socioeco.org/docs/a_economia_solid_ria_como_meio_para_o_desenvolviment o_sustent_vel-_caso_do_banco_palmas-1.pdf. Acesso em: 13 jun. 2019.

SOUZA, Nali de Jesus. Desenvolvimento Econômico. 3. ed. São Paulo: Atlas, 2012.

SOUZA, Washington Peluso Albino de. Teoria da Constituição Econômica. Belo Horizonte: Del Rey, 2002.

SOUZA, Washington Peluso Albino de; CAMARGO, Ricardo Antônio Lucas; TORELLY, Paulo Peretti. Constituição Econômica e Pacto Federativo. Porto Alegre: Núria Fabris, 2015.

TOSTA, André Ribeiro. A intervenção do Município no Domínio Econômico e o Regime Jurídico dos Contratos da Petrobrás. São Paulo: PUC/SP, 2014. 